\title{
A review of forecasting models for new products
}

\author{
Marta Mas-Machuca ${ }^{1}$, Marina Sainz ${ }^{2}$, Carme Martinez-Costa ${ }^{2}$ \\ ${ }^{1}$ Universitat Internacional de Catalunya, ${ }^{2}$ Universitat Politècnica de Catalunya (Spain) \\ mmas@uic.es, msainzcomas@gmail.com, mcarme.martinez@upc.edu
}

Received October, 2013

\section{Abstract}

Purpose: The main objective of this article is to present an up-to-date review of new product forecasting techniques.

Design/methodology/approach: A systematic review of forecasting journals was carried out using the ISI-Web of Knowledge database. Several articles were retrieved and examined, and forecasting techniques relevant to this study were selected and assessed.

Findings: The strengths, weaknesses and applications of the main forecasting models are discussed to examine trends and set future challenges.

Research limitations/implications: A theoretical reference framework for forecasting techniques classified into judgmental, consumer/market research, cause-effect and artificial intelligence is proposed. Future research can assess these models qualitatively.

Practical implications: Companies are currently motivated to launch new products and thus attract new customers to expand their market share. In order to reduce uncertainty and risk, many companies go to extra lengths to forecast sales accurately using several techniques.

Originality/value: This article outlines new lines of research on the improvement of new product performance which will aid managers in decision making and allow companies to sustain their competitive advantages in this challenging world. 
Keywords: Forecasting, new product, forecasting techniques

Jel Codes: M31, C1, C2

\section{Introduction}

In a constantly evolving world, the forecasting of new and extremely new products is key to the economic welfare. New product sales forecasting must deal with major problems caused by lack of data and the uncertainty of how breakthrough technologies and products will be accepted by consumers. Assmus (1984) defined new product forecasting as one of the most difficult and critical management tasks.

An example of the increasing importance of new product forecasting is the emergence of several initiatives to improve results, such as the M-Competition. This contest is run by a group led by Prof. Makridakis and has been held four times now (M4-Competition, 2010). It aims to investigate new forecasting models in order to provide more accurate information about future sales.

The most recent challenge is, however, how to forecast sales in case of lack of data. Obviously, it is not possible to use previous sets of sales data as the product has not been launched yet, and therefore not purchased; actually, costumers are unlikely to have ever seen the product before. So like a dog chasing its tail, sales data are needed to forecast, forecasts are needed to take crucial decisions about the product launching but without launching there are no sales data. The problem gets worse when dealing with frequently purchased products. For this reason, not all methods are adequate for this forecasting exercise.

Also, there is a large number of forecasting models but, as previous works show, some of them have been underutilized (Mahajan, 1990). One reason could be the low success rate of new products (Wind \& Mahajan, 1997).

The principal objective of this article is to present an updated review of new product forecasting models with an emphasis on the techniques used. The main models are analysed by discussing their strengths, weaknesses and applications.

This paper is organized into three sections. The following section presents the main contributions of previous works. Section 3 reviews selected new product forecasting techniques. Finally, the article concludes with a discussion of the models and proposes new interesting lines of research. 


\section{Previous works}

Wind (1974) analysed the new product forecasting models in order to establish selection criteria for the most suitable model according to company needs. Later, Mahajan and Wind (1988) proposed an evaluation (highlighting strengths and weaknesses) of previous new product forecasting models in industry and academia. Moreover, they suggested six areas to improve research and implementation of these models. In this sense, Assmus (1984) classified new product forecasting models into two types: trial-repeat models, which break down total sales into trial purchase sales and repeat purchase sales (e.g. diffusion, behavioral and managerial models), and competitive structural models, which estimate the market share that the new product will capture within a well-defined market with given competitors (e.g. buyer behavior and market structure models).

Another relevant survey by Hardie, Fader and Wisniewsky (1998) dealt with the problem of new product trial forecasting methods in consumer packaged goods. The questions of "Which trial models provide the best forecasts? and "When and why do these models perform best?" were answered, and a comprehensive investigation of eight leading published models was conducted and their forecasting accuracy analysed.

According to Lynn, Schnaars and Skov (1999), high-tech industries and low-tech industries use different forecasting models. In their study, seventy-six new industrial product projects were examined. It was concluded that high-tech businesses tend to use highly qualitative new product forecasting methods (mainly based on internal data) while low-tech businesses rely more on quantitative techniques such as customer surveys.

Ozer (1999) reviewed the widely cited new product models based on their objectives, applicability to different products, data requirements, suitable environments, time frames and type of diagnostics information. Later, Kahn (2002) presented an exploratory research to describe the new product forecasting effort, techniques and accuracy. More recently, Lawrence, Goodwin, O'connor and Önkal (2006) focused their research on judgmental approaches to forecasting.

Other previous works review diffusion forecasting models only, such as Parker (1994) and Mahajan, Muller and Bass (1990), or discuss pre-test market models only, like Shocker and Hall (1986) and Urban and Katz (1983). More recently, Meade and Islam (2006) offered a state of the art of innovation diffusion forecasting models with an emphasis on their improvements of forecasting accuracy.

Table 1 is a summary of the main contributions, classification criteria and type of models reviewed in the main surveys on new product forecasting. 


\begin{tabular}{|c|c|c|c|}
\hline $\begin{array}{l}\text { Review } \\
\text { article }\end{array}$ & Main contribution & $\begin{array}{l}\text { Classification } \\
\text { criteria/Approach }\end{array}$ & Reviewed models \\
\hline $\begin{array}{l}\text { Wind } \\
(1974)\end{array}$ & $\begin{array}{l}\text { Classification } \\
\text { framework (eight sets } \\
\text { of characteristics) and } \\
\text { evaluation of new } \\
\text { product forecasting } \\
\text { models }\end{array}$ & $\begin{array}{l}\text { Purpose of the model } \\
\text { Type of products and } \\
\text { services } \\
\text { Unit and level of analysis } \\
\text { Model format } \\
\text { Dependent variables } \\
\text { Independent variables } \\
\text { Required data } \\
\text { Analytical procedures }\end{array}$ & $\begin{array}{l}\text { According to Purpose of the } \\
\text { model } \\
\text { Forecasting of aggregate market } \\
\text { demand vs. trial or repeat } \\
\text { purchase forecasting } \\
\text { First purchase models vs. repeat } \\
\text { purchase models } \\
\text { Prediction vs. prediction and } \\
\text { diagnostics }\end{array}$ \\
\hline $\begin{array}{l}\text { Assmus } \\
\text { (1984) }\end{array}$ & & $\begin{array}{l}\text { Trial-repeat models, } \\
\text { which break down total } \\
\text { sales into trial purchase } \\
\text { sales and repeat } \\
\text { purchase sales } \\
\text { Competitive structural } \\
\text { models estimate the } \\
\text { market share that the } \\
\text { new product will capture } \\
\text { within a well-defined } \\
\text { market with given } \\
\text { competitors }\end{array}$ & $\begin{array}{l}\text { Diffusion models } \\
\text { Behavioral models } \\
\text { Managerial models } \\
\text { Buyer behavior models } \\
\text { Market structure models }\end{array}$ \\
\hline $\begin{array}{l}\text { Mahajan } \\
\text { \& Wind } \\
(1988)\end{array}$ & $\begin{array}{l}\text { Comparative } \\
\text { evaluation from } 8 \\
\text { review papers }\end{array}$ & $\begin{array}{l}\text { Stage in the new product } \\
\text { development process }\end{array}$ & $\begin{array}{l}\text { Concept test models } \\
\text { Pre-test market models } \\
\text { Early sales models }\end{array}$ \\
\hline $\begin{array}{l}\text { Hardie et } \\
\text { al. } \\
(1998)\end{array}$ & $\begin{array}{l}\text { Comprehensive } \\
\text { investigation of } 8 \\
\text { leading published } \\
\text { models in consumer } \\
\text { packaged goods }\end{array}$ & $\begin{array}{l}\text { New product trial } \\
\text { forecasting models }\end{array}$ & $\begin{array}{l}\text { Exponential with "Never Triers" } \\
\text { Exponential with "Never Triers"+ } \\
\text { "Stretch" factor. } \\
\text { Exponential-Gamma } \\
\text { Exponential-Gamma with "Never } \\
\text { Triers" } \\
\text { Weibull with "Never Triers" } \\
\text { Lognormal } \\
\text { "Double-Exponential" } \\
\text { Bass Model }\end{array}$ \\
\hline $\begin{array}{l}\text { Lynn et } \\
\text { al. } \\
\text { (1999) }\end{array}$ & $\begin{array}{l}\text { Study of } 76 \text { new } \\
\text { industrial product } \\
\text { projects: } 38 \text { successes } \\
\text { and } 38 \text { failures }\end{array}$ & $\begin{array}{l}\text { Source data: internal or } \\
\text { external, and qualitative } \\
\text { or quantitative }\end{array}$ & $\begin{array}{l}\text { External Expert Judgment } \\
\text { Internal Expert Judgment } \\
\text { External Brainstorming } \\
\text { Internal Brainstorming } \\
\text { Focus Group } \\
\text { One-On-One Interview with } \\
\text { Customers } \\
\text { Delphi Method } \\
\text { One-On-One Interview with } \\
\text { Salespeople } \\
\text { Limited Rollout } \\
\text { Formal Survey of Customers } \\
\text { Time Series Analysis } \\
\text { Regression }\end{array}$ \\
\hline
\end{tabular}




\begin{tabular}{|c|c|c|c|}
\hline $\begin{array}{l}\text { Review } \\
\text { article }\end{array}$ & Main contribution & $\begin{array}{l}\text { Classification } \\
\text { criteria/Approach }\end{array}$ & Reviewed models \\
\hline $\begin{array}{l}\text { Ozer } \\
(1999)\end{array}$ & $\begin{array}{l}\text { Critical review with an } \\
\text { emphasis on the } \\
\text { following factors: } \\
\text { objectives, } \\
\text { applicability to } \\
\text { different products, } \\
\text { data requirements, } \\
\text { suitable environments } \\
\text { and times frames, and } \\
\text { diagnosis. }\end{array}$ & $\begin{array}{l}\text { Applicability to different } \\
\text { products, data } \\
\text { requirements, suitable } \\
\text { environments, time } \\
\text { frames and type of } \\
\text { diagnostics information }\end{array}$ & $\begin{array}{l}\text { Concept Testing: Analogies } \\
\text { Concept Testing: Expert Opinions } \\
\text { Concept Testing: Purchase } \\
\text { Intentions } \\
\text { Concept Testing: Multiattribute } \\
\text { Approaches } \\
\text { Concept Testing: Focus Groups } \\
\text { Concept Testing: SA\&IA } \\
\text { Prototype Testing } \\
\text { Pre-Test Market } \\
\text { Test Market } \\
\text { Launch: Diffusion } \\
\text { Brand Equity Analysis } \\
\text { Need/Usage Context Analysis } \\
\text { Environmental Scanning } \\
\text { Portfolio Approach } \\
\text { Pattern Recognition } \\
\text { Internet } \\
\text { Alliance } \\
\text { Value-Chain Approach } \\
\text { Straight Judgment-Vicarious } \\
\text { Input }\end{array}$ \\
\hline $\begin{array}{l}\text { Kahn } \\
(2002)\end{array}$ & $\begin{array}{l}\text { Exploratory } \\
\text { investigation of new } \\
\text { product forecasting } \\
\text { practices }\end{array}$ & $\begin{array}{l}\text { Explore current new } \\
\text { product forecasting } \\
\text { practices during the } \\
\text { commercialisation/ } \\
\text { launch stage }\end{array}$ & $\begin{array}{l}\text { Customer/market research } \\
\text { Jury of executive opinion } \\
\text { Sales force composite } \\
\text { Looks-like analysis } \\
\text { Trend line analysis } \\
\text { Moving average } \\
\text { Scenario analysis } \\
\text { Exponential smoothing } \\
\text { techniques } \\
\text { Experience curves } \\
\text { Market Analysis model } \\
\text { Delphi model } \\
\text { Linear Regression } \\
\text { Decision trees } \\
\text { Simulation } \\
\text { Expert system } \\
\text { Non linear regression } \\
\text { Pre-cursor curves } \\
\text { Box-Jenkins techniques } \\
\text { Neural networks }\end{array}$ \\
\hline $\begin{array}{l}\text { Lawrence } \\
\text { et al. } \\
(2006)\end{array}$ & $\begin{array}{l}25-y e a r \text { progress } \\
\text { review of judgmental } \\
\text { forecasting }\end{array}$ & $\begin{array}{l}\text { Judgmental models (over } \\
200 \text { studies are } \\
\text { referenced in this review) }\end{array}$ & $\begin{array}{l}\text { Judgmental probability forecasts } \\
\text { and prediction intervals }\end{array}$ \\
\hline $\begin{array}{l}\text { Meade \& } \\
\text { Islam } \\
(2006)\end{array}$ & $\begin{array}{l}25 \text {-year progress } \\
\text { review of forecasting } \\
\text { of the diffusion of } \\
\text { innovations }\end{array}$ & $\begin{array}{l}\text { Innovation diffusion } \\
\text { models }\end{array}$ & $\begin{array}{l}\text { Exploratory variables in diffusion } \\
\text { models } \\
\text { Estimation issues in single } \\
\text { diffusion models (Bass models) } \\
\text { Modeling of constrained diffusion } \\
\text { Modeling of diffusion of multiple } \\
\text { sub-categories } \\
\text { Modeling of diffusion across } \\
\text { several countries } \\
\text { Modeling of diffusion across } \\
\text { several generations of } \\
\text { technology }\end{array}$ \\
\hline
\end{tabular}

Table 1 . Summary of previous works 
After this literature review of previous works, a comprehensive, up-to-date survey of the main new product forecasting models is provided. In addition, the strengths and weaknesses of selected models are highlighted and future lines of research are suggested.

\section{Main contribution}

The classification used in this paper is based on Kahn (2006) classification, which divides the analytical models into judgmental methods, consumer/market research, cause-effect models and artificial intelligence methods (see Figure 1 ). Judgmental methods rely on forecaster past experience or stakeholder opinions. Consumer/market research is conducted according to the stage of the product creation process and is usually related to existing commercial software. Cause-effect models develop a solution using a mathematical relationship between data, and finally, artificial intelligence methods mix both experience and analytical procedures.

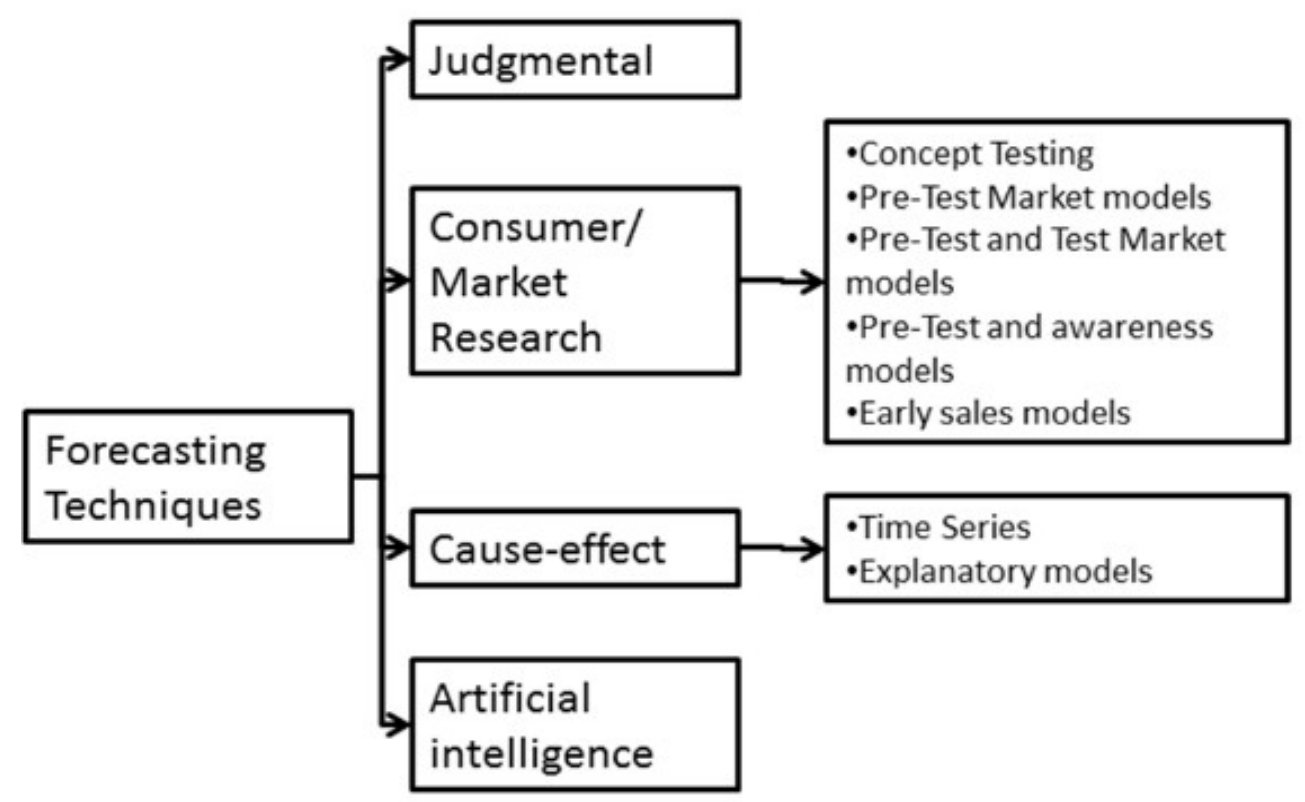

Figure 1. Classification of new product forecasting techniques

The next section describes the techniques and their main characteristics. 


\subsection{Judgmental methods}

Judgmental methods are based on the educated opinion of several experts to forecast future sales. They have traditionally been disregarded due to their strong dependence on user experience, commonly leading to inaccuracy, and the risk involved. However, according to Sanders and Manrodt (2003) and as stated in several surveys and analyses, managers still prefer judgmental methods over other more complex quantitative methods. The objective of the former is to turn experience, judgment and intuition into a formal forecast (Kahn, 2006).

Among judgmental methods, we can find Delphi, product life-cycle analogy, expert judgment, scenario writing, subject approach, sales force option, decision trees and assumption-based modeling. Some of these techniques, e.g. expert judgment and scenario writing, involve more risk to produce a biased forecast, especially when the innovation on the product is high.

The Delphi method may be characterized as a method for structuring a group communication process so that the process is effective in allowing a group of individuals, as a whole, to deal with a complex problem (Linstone \& Turoff, 1975). To accomplish this "structured communication" there is provided: some feedback of individual contributions of information and knowledge; some assessment of the group judgement or view; some opportunity for individuals to revise view; and some degree of anonymity for the individual responses. Two types of forecasting information are collected. First is the forecast itself, usually in numerical form. The second type of information is the rationales behind the forecast. The goal is to achieve a consensus on the forecast (Kahn, 2006).

Product life-cycle analogy is a good option when the new product is an extension of a previously existing product or when it is easily comparable with other existing products. It can also provide good information in the case of commonly purchased products as innovations are not usually big break-throughs. Gartner and Thomas (1993) stated that extensive marketing research has proven to increase the accuracy of sales prediction when used together with other methods.

When launching a new product, expert opinion can be highly valuable. Specially, in the case of break-through products, expert experience can lead to biased conclusions. The recommendation is to use judgmental methods as complements to other quantitative methodologies.

The authors of several expert opinion models decided to combine qualitative methods with judgmental methods in order to increase accuracy and obtain top manager approval. For 
instance, Ching-Chin, Ieong Ka Ieng, Ling-Ling and Ling-Chieh (2010) give managers the possibility to adjust the final forecasting results according to their beliefs and knowledge.

\subsection{Consumer and Market Research}

This section describes the most used software applications in new product forecasting. The forecasting process starts much before than the launching of the new product since in the first stages of design forecasters play an important role in avoiding product failure in the market. It is widely agreed that the steps of product development are: idea and concept screening, consumer-based concept test, pre-test, test market and launching. Different models and software applications can be used depending on the stage of product development.

Mahajan and Wind (1988) described the product decision process as shown in Figure 1. Firstly, it is necessary to develop innovative ideas and choose the best ones by comparison with a benchmark. Concept test evaluates consumer response to the new product idea. Fader and Hardie (2001) described pre-test market evaluation as a necessary step to avoid costly decisions. Data can be gathered in two different ways, i.e. by exposing consumers to the new product and measuring their purchase intention and by replacing the purchase intention stage by a simulated shopping task in a mock store. The next step is test market assessment; companies launch the product in a controlled environment, usually a small town or a few selected shops, and extrapolate the results to the whole national market. Finally, the launching of the product can be regional, national or worldwide.

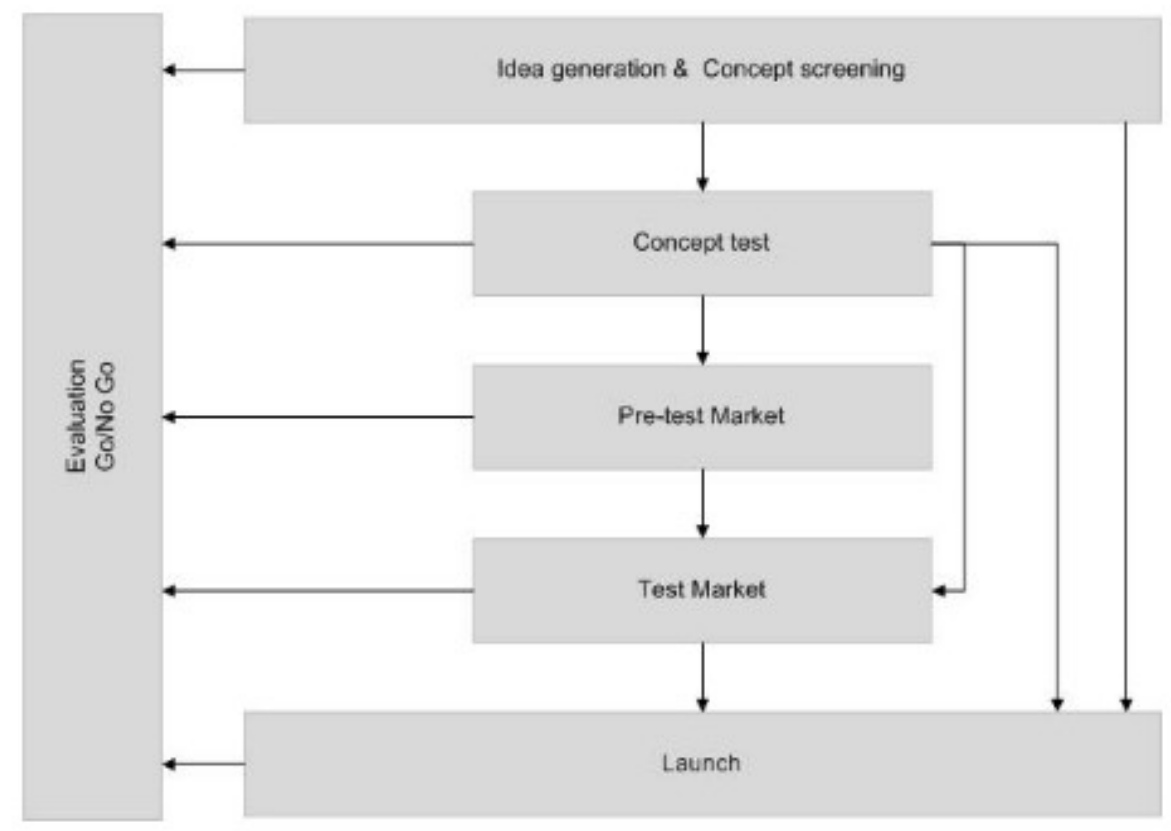

Figure 2. Product decision stages 
Given the huge number of sales forecasting software, only the new product sales forecasting software applications most commonly used by managers were examined.

Mahajan and Wind (1988) established the following classification of new product forecasting software according to the stage of product development.

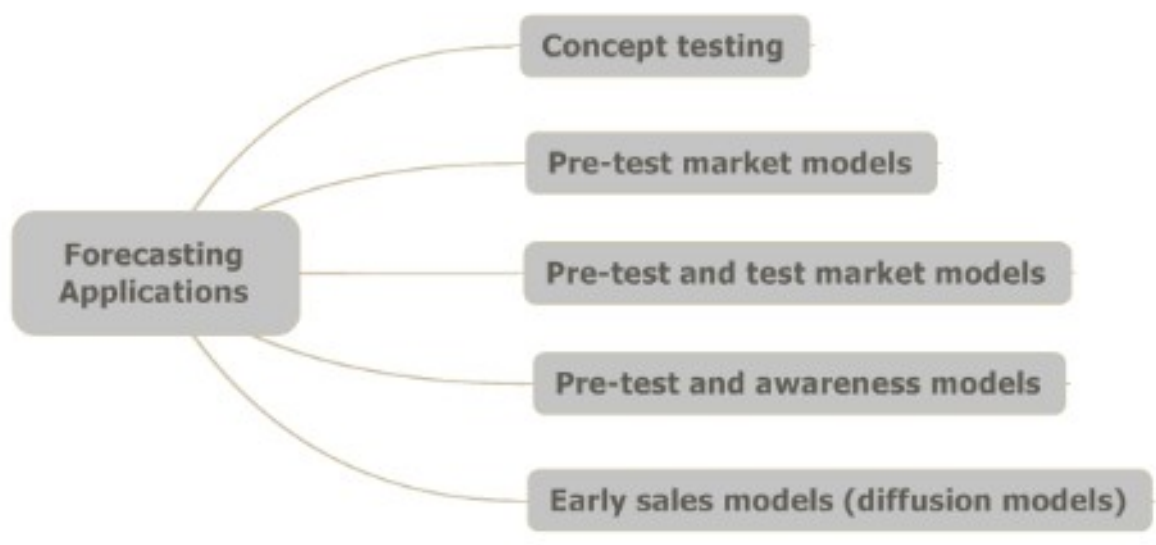

Figure 3. Classification of forecasting software

Concept test models are suitable for all types of products, especially those in an established product category. However, they lack accuracy when product diffusion occurs mostly through word of mouth, measurement of depth is essential to obtain market loyalty, retail promotions affect sales significantly or the product is an innovative breakthrough, among other situations. Results are often short term.

Pre-test market models are most appropriate for frequently purchased consumer products with some exceptions. For instance, they are not suitable for new products, if the market for the product category is growing or the above conditions for concept test models. In general, market sales estimates are forecast annually. Some of the best-known software included in pre-test market models are ASSESSOR, BASES II and NEWS/PLANNER.

According to Urban and Hauser (1993), the 'full proposition' analyses are sufficiently accurate to identify most winners and eliminate most losers. They provide an effective way to control the risks of failure and supply actionable managerial diagnostics to improve the product. Pretest market analysis should be conducted well in advance to stop investing should the analysis indicate that the product is likely to be a failure. Apart from giving a go/no-go answer, the analysis should provide a diagnostic about possible improvements and strong points, whether the product is likely to be a failure (30-50\% for packaged goods) or the go decision has been 
made. Finally, the cost of the research is key in deciding whether to run it. Pre-test market research should not be very expensive in time or money.

Mahajan and Wind (1988) defended that test market models are also appropriate for frequently purchased consumer goods except when the same results can be obtained from pre-test market models, when time, cost and accuracy are critical or when the competitors are likely to influence the results or mitigate the competitive advantage.

Urban and Hauser (1993) defined three different types of test markets according to the strategy chosen. The first strategy is to replicate national sales. The company tries to replicate the same environment of a national launch but only in one or two middle sized cities, with bigger cities involving higher costs. The cities should be representative enough to allow sales results to be extrapolated to national sales results as accurately as possible. The second strategy consists in experimenting on marketing variables, sometimes using a controlled store. Promotions, coupons and displays are limited to the shop area. The last strategy relies on the correction of mistakes by extrapolating results from local to national level.

Early sales models, also known as diffusion models, are thought for consumer durables and are not suitable for seasonal or cyclical products, or when it is impossible to distinguish between trial and repeat purchase sales.

Comparing the performance of software products is a difficult task because some provide results of cumulative sales while others compile information, distinguishing between first and repeat sales. Hence, the most used new product forecasting software applications are discussed without comparing their performance.

Mahajan and Wind (1988) classified existing software depending on the stage of product development it focuses on. The following graph adapts this classification by including some interesting software developed in the past years.

Mahajan and Wind's (1988) analysis is very thorough and includes non-commercial models. The classification by stage of product development based on these authors includes the most commonly used current commercial software like BASES, NEWS and ASSESSOR, together with other software extensively used in companies, such as MicroTest or DESIGNOR.

NEWS stands for New Product Warning System and was developed by BBDO. It provides forecasts on awareness, trial, repeat, usage, sales and others. Moreover, it points out the strengths and weaknesses of the marketing plan as well as making recommendations on product concept and performance, advertising strategy and strategic decisions for the brand. 


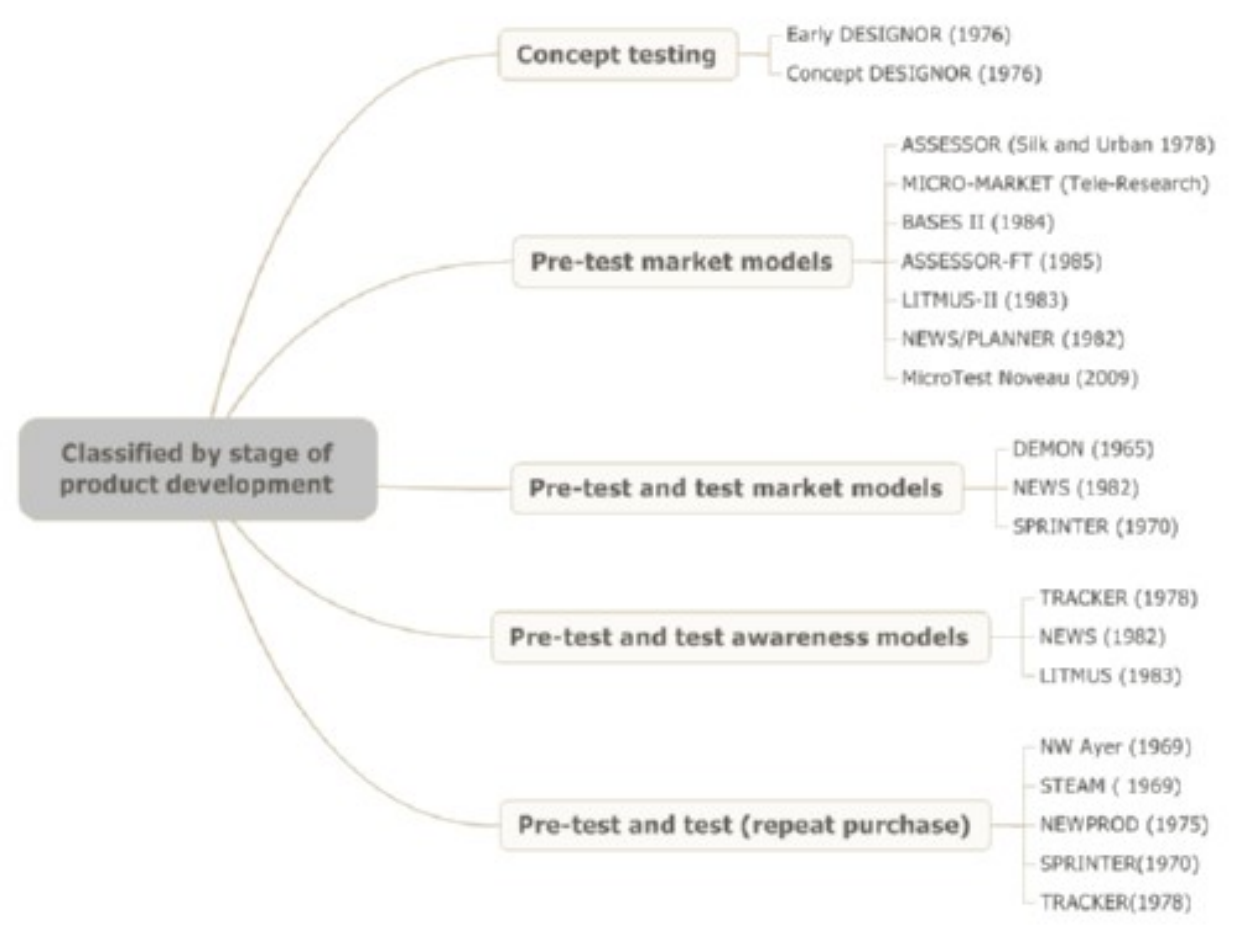

Figure 4. Adaptation of Mahajan and Wind's classification

NEWS is the evolution of DEMON, which was developed in 1965 after 20 years of forecasting expertise. These models, used to forecast sales or brand awareness, are not based on any quantitative models, but rather on marketing theory, consumer behavior, empirical evidence and intuition.

NEWS is especially suitable for the following situations: when products are not seasonal, consumers become aware of products mainly through advertising, or products are conveniently available for purchase. When purchases become sustained over time, products are not new anymore and then NEWS is not appropriate. The formulae used by NEWS can be consulted in Pringle, Wilson and Brody (1982).

BASES, developed by Nielsen, is the leader in the field, with almost $50 \%$ of the market, as stated by Wherry (2006). Like other similar software, BASES consists of several modules according to different needs. Thus, companies purchase the most adequate modules for their sales forecasts.

According to Nielsen's webpage, the packages specially designed to forecast and improve new products are: pre-BASES, BASES I, BASES II, BASES restager, BASES-suite, ScanTrack, Retail Index and HomeScan. 
BASES I and BASES II are the two main software applications for new product forecasting. BASES I is a concept-only study which provides detailed information for possible choices during the commercialisation stage. It offers sales estimates, consultation on how to improve the odds for consumer adoption and the productivity of the marketing plan, as well as a very powerful competitor database for comparisons to peer groups.

BASES II complements BASES I by placing product prototypes with consumers. BASES II also provides assessment about long-term initiative viability. On the other hand, BASES restager accurately determines the impact of new product development and strategic decisions about product brands.

According to Wherry (2006), BASES owns a database of 60000 products launched after 1370 validation studies with an accuracy level within $9 \%$. BASES has recently partnered with P\&G, becoming the only licensee of Virtual Launch, a new system which uses virtual marketing materials and online "shopping trips" to better understand consumer purchase intention and capture the current marketing environment.

ASSESSOR is a pre-test market forecasting software tool marketed by $M / A / R / C$ Group. The right time for implementation is after the design, development and test of the new product but before the launch. ASSESSOR consists of two models, i.e. the preference model and the trialand-repeat model.

ASSESSOR allows managers to develop forecasts of sales volumes and long-term market shares of new products without the need of a test market, which increases costs significantly. Moreover, it helps understand the effects of advertisement methods and quotes on total sales, as well as avoiding the development and production of new products with little or no commercial potential. ASSESSOR also evaluates and proposes the most appropriate marketing plans and advertising possibilities.

Unlike BASES, ASSESSOR does not rely on historical data or benchmarks but analyses product competitive market and trade-offs. For this reason, ASSESSOR has its own forecasting models, which can be consulted online in Lilien, Rangaswamy and De Bruyn (2007).

DESIGNOR was first developed in 1976 to forecast consumer goods sales and is currently marketed by Ipsos Marketing. Thirty years of experience have nurtured a database of 10000 new products tested and optimised within 250 categories.

Wherry (2006) explained that DESIGNOR uses a convergent model which integrates behavioral and attitudinal models with loyalty and fragmentation market models. Like other commercial software, it is divided into several modules seeking to improve different stages of the product 
development: Early DESIGNOR, to select the best product concepts; Concept DESIGNOR, to improve these concepts, and STM DESIGNOR, to forecast sales results after the launch.

Developers have designed a system based on three key measurements, i.e. relevance, expensiveness and differentiation, identified as critical to success.

In 2009 Kantar Japan launched a new version of MicroTest: MicroTest Nouveau. This software relies on a database of 40000 test cases to measure purchase intention like BASES.

The model banks on the behavior of individual customers to forecast future sales but also to detect potential barriers of entry and improve the marketing plan. It is suitable for new products in new categories.

\subsection{Cause-effect methods}

As the cause-effect group includes a vast variety of forecasting methods, a sub-classification is necessary. Multiple definitions and classifications can be found, one of the oldest being by Wind (1974). Our division was first proposed by Makridakis and Wheelwright (1998), who distinguished between chronological series (or time series) and explanatory methods, which include regression and econometric methods. Makridakis \& Wheelwright (1998) stated that time series methods are more accurate in forecasting in the short term while explanatory methods provide extensive knowledge of factors affecting the forecast.

\subsubsection{Time series methods}

Time series methods use known historical sales and data to predict future sales. Included in this group are random walk (naïve) model, moving average and exponential smoothing.

Random walk or Naïve I is the simplest method. Widely used to forecast the stock market value, random walk gives excellent results despite its simplicity. This method uses the last real value to predict the next period, which is a good forecast if the sales value between periods does not change significantly.

Random walk does not give satisfactory results when seasonality is present in the data set. Naïve II should be used in these cases. This method consists in removing the seasonality and then applying the same methodology as in Naïve I, therefore remaining a very simple, easy to understand method. 
Due to their simplicity and in the current scenario of a new product launch, Naïve I and II can be considered good forecasting methods, although with much caution as in the first months sales can be volatile and results misleading.

Moving average assumes that future sales will be an average of past performance rather than following a linear trend. This method minimises the impact of randomness as it provides an average of several values. Five levels of simplicity can be found, i.e. simple, cumulative, weighted, exponential and autoregressive.

Simple moving average is the unweighted mean of previous $\mathrm{N}$ datum points, larger $\mathrm{N}$ values lead to a reduced impact of last periods on final results. This method works well with new product forecasting as long as $\mathrm{N}$ is defined properly. This parameter, usually decided by experienced forecasters, is crucial for accurate results.

Cumulative moving average is the unweighted mean of previous $\mathrm{N}$ datum points, including the current period. In this case, the mean is calculated by adding all previous plus current data and the result is divided by the number of periods. As old data are not dropped, their effect is mixed with that of current data. In new product sales forecasting, where few data are available and the last data set is extremely important because of possible large sales differences between periods, this method may lead to inaccuracy.

Weighted moving average consists in giving a certain weight to each period of data divided by the sum of all weights or a triangle number $(n *(n+1) / 2)$. This moving average is widely used for pixelisation but of little use in new sales forecasting. Similarly, exponential moving average, which involves weighted factors that decrease exponentially, is not adequate for our study as we are seeking to forecast a typical growing sales model.

Autoregressive moving average (ARMA) can be called Box-Jenkins, as the Box-Jenkins methodology usually uses it for estimation. ARIMA or autoregressive integrated moving average is the generalisation of ARMA. ARMA considers that future sales depend on past sales and past errors between prognosis and real sales values. The general equation is as follows:

$$
Y_{t}=\phi_{1} Y_{t-1}+\phi_{2} Y_{t-2}+\cdots+\phi_{p} Y_{t-p}+e_{t}-\theta_{1} e_{t-1}-\theta_{2} e_{t-2}-\cdots-\theta_{q} e_{t-q}
$$

where the length and number of components of the equation depend on $p$ and $q$ values. These are decided by the forecaster by analysing the autocorrelation factors of the data and their possible trend and cycle, but usually fall between 0 and 3. If the data are not correlated at all, the values are closer to 0 while more auto-correlated data lead to higher values. Box-Jenkins is an iterative methodology for finding the best $\mathrm{p}$ and $\mathrm{q}$ values and estimating the best forecast (Makridakis \& Wheelwright, 1998). 
What can be understood of this equation analysis is that to extract accurate autocorrelation values and fit the ARMA function to the data properly, large amounts of data are necessary. In this case study where data are valuable and scarce, the probabilities to find the appropriate autocorrelation values are low, resulting in inaccurate forecasts.

Exponential smoothing provides forecasts depending on an alpha value $(0 \leq \alpha \leq 1)$ which determines the weight of the last periods of data. Large alpha values result in faster damping; thus, the response to data variation is very high. For alpha values close to 0 , old data become more important and the final result is less variable. There are several variations of exponential smoothing, namely simple (Brown), additive trend (Holt), damped additive (Gardner \& McKenzie, 1985), multiplicative (Pegel) and damped multiplicative (Taylor). All these methods can be adapted to any seasonality in the data.

A description and formulation of all exponential smoothing methods, including variations for seasonality, can be found in (Gardner, 2005). For good accuracy, a previous analysis of seasonality and trend is necessary.

Time horizon is a problematic as well. Makridakis and Wheelwright (1998) suggests the use of different exponential smoothing techniques. For annual forecasting, the most adequate is Holt exponential smoothing; all exponential smoothing methods are appropriate for three-month forecasting while monthly forecasting can be successfully done by Brown exponential smoothing. Makridakis and Wheelwright (1998) proposes a combination of Brown, Holt and damped methods due to their complementary properties.

Other techniques are trend-line analysis, where a line is fit to a set of data (graphically or mathematically), and looks-like analysis or analogous forecasting, which attempts to map sales of other products onto the product being forecast. This method is applied to line extensions using sales of previous product line introductions to profile sales of the new product.

\subsubsection{Explanatory methods}

Explanatory methods include regression analysis and econometric models. According to Makridakis and Wheelwright (1998), these techniques provide more knowledge on the factors influencing the forecast result but less accuracy.

Regression analysis is known to be a very specific, time consuming method. Representing the outcome as a (linear or nonlinear) regression of several factors involves large amounts of data and long statistical analysis. This method is automatically excluded for new product sales 
forecasting since the use of only four or fewer periods of data yields meaningless results.

Econometric models are a wide field of study. The three options used by Ching-Chin et al., (2010), i.e. sales index, Taylor series and diffusion models, are presented below.

Sales index estimates new product sales using data about the whole product class. Therefore, it is not applicable if no products in the same class have recently been launched. The method consists in calculating a sales forecast ratio assuming that the new product follows a trend similar to that of the other products in the same class. Consequently, sales index is suitable for new sales forecasting as long as current data about the same product class are available.

Taylor series, an approximation derived from truncated Taylor series, was proposed by (Mentzer \& Moon, 2005) for cases of poor data availability, e.g. a technology breakthrough or a new product launch.

Because of the newness and interesting applications of this method, we give the formula:

$$
\begin{gathered}
F_{\theta, t}=S R_{\theta, t-1}\left[1+\frac{1}{1 !}+\frac{1}{2 !}+\cdots+\frac{1}{(N-1) !}\right]-S R_{\theta, t-2}\left[\frac{1}{1 !}+\frac{2}{2 !}+\cdots+\frac{N-1}{(N-1) !}\right]+\cdots \\
+(-1)^{j}\left[S R_{\theta, N-j} \sum \frac{C_{j}^{k}}{k !}\right]+\cdots+(-1)^{j} \frac{S R_{\theta, 1}}{(N-1) !}
\end{gathered}
$$

where given $\mathrm{m}$ periods available and $\mathrm{N}$ is a parameter with a value between 1 and $\mathrm{m}$ depending on the number of datum points used, and are the sales of product " $e$ " at period " $t$ " after removing the effects.

Diffusion models involve a very large number of forecasting models. They are all based on the idea that a product life-cycle usually follows an S-shaped curve which several models try to reproduce using certain parameters. Some diffusion models only consider first buyers (or innovators), others also include late adopters (or imitators) while a third group does not make a distinction among buyers and only considers the total aggregate sales.

Models distinguishing between innovators and imitators need special test and pre-test data. As mentioned in (Michelfelder \& Morrin, 2006), the estimation of the total sales only requires the first post-launch data assuming that the launch is successful. The model itself is unable to predict the success or failure of the launch.

Regarding new product models which do not distinguish between first and repeat sales, (Morrison, 1996) proposes the logarithmic (or logistic) and Gompertz. 
These two models are suitable to forecast new products with no sales history, forecast relatively new products with a short sales history, and determine the characteristics of the diffusion process using the history of mature products.

Both models require three parameters: long-run saturation level (S), delay factor $(A)$ and inflection point (I). When estimating really new product sales, these parameters are often unknown or hard to estimate. One option is to previously calculate them for a mature product of the same family or class. Like most models, these two also assume that the product's life cycle follows an S-shape curve.

In the logistics curve model, the inflection point is reached at exactly $50 \%$ of the long-run saturation level. Therefore, the curve is symmetric. The formula used is

$$
F(t)=\frac{s}{1+B \theta^{A t}} \quad \text { where } B=e^{I A}
$$

In the Gompertz model, the inflection point is reached at $36.8 \%$ of the long-run saturation level, reflecting slower product penetration into the market as all the other parameters do have the same value. Higher delay factors are more similar to a logarithmic curve after its point of inflection. The formula is as follows:

$$
F(t)=S e^{-A} e^{-B t} \quad \text { Where } \quad=\left|\ln \left(\frac{\ln \left(\frac{\frac{0.868 * 5}{S}}{-A}\right)}{I}\right)\right|
$$

Logarithmic and Gompertz are suitable for new products as long as the forecaster can estimate "S", "A" and "I" or calculate them approximately using data of a same product class. No large data sets of the new product sales are required.

Hardie et al. (1998) studied eight diffusion models for measuring new product penetration (or cumulative trial) up to some point in time. The models were tested on their robustness and accuracy. As said before, it was concluded that simpler models perform better than more sophisticated ones. Thus, exponential with never triers, exponential with never triers and stretch factor, exponential gamma and exponential gamma with never triers proved to be more accurate than Weibbull gamma with never triers, lognormal-lognormal, double exponential and Bass model. Moreover, exponential gamma and exponential gamma with never triers stand out for their robustness.

Bass model (Bass, 1969) is the best known diffusion model. It describes how products are adopted by new consumers as an interaction of users and potential users (innovators and 
imitators). The model assumes that the probability of a new purchase at any time is linearly related to the number of previous buyers, and excludes repeat purchases; only first purchases are taken into account. Consequently, the Bass model is not appropriate for frequently purchased consumer products; it was specifically designed for new product forecasting. The formula is as follows:

$$
F(t)=p * m+(q-p) Y(t)-\frac{q}{m}(Y(t))^{2}
$$

where " $\mathrm{m}$ " is the total number of purchases in the time period, " $p$ " is the coefficient of innovation and " $q$ " is the coefficient of imitation. The forecast accuracy will depend on the value of these parameters, whose calculation requires at least data from three time periods (Bass, 1969).

The Bass model has been extensively studied and used. A number of modified forms have been developed, such as a generalized Bass model which includes other marketing variables (Bass, Trichy \& Dipak, 1994) or adaptations to other growth curves such as Meta-Bass or augmented Meta-Bass (Sood, James \& Tellis, 2009).

\subsection{Artificial intelligence methods}

Artificial intelligence methods have the ability to improve over time with the incorporation of new data. They are a midway between commercial software and strictly mathematical algorithms. Expert systems and neural networks are defined below as examples of these methods.

Expert systems is a wide field of study; actually all software products combining several forecast techniques could be included in this group. Rule-based forecasting is an expert system that develops forecasts using judgmental knowledge reflected in rules. The adequacy of new product rule-based forecasting highly depends on the knowledge used to develop rules and extrapolations. The judgmental nuance is provided by forecaster expertise, manager expectations and historical reviews. The rules are used to give different weights to empirical forecasts made by several methods. Hence, rule-based forecasting uses qualitative knowledge to combine the results of quantitative forecasts (Adyaa, Armstrong, Collopy \& Kennedy, 2000).

Quantitative expert systems include all kinds of forecast software applications using mathematical modelling. Because of the huge diversity of applications, it is impossible to mention them all. Their appropriateness is only related to the forecasting methods used, which should be suitable for estimating really new product sales. 
The rule of simplicity applies to most expert systems. As mentioned in Fader and Hardie (2005), simpler applications are generally better accepted by users, as it is possible to reproduce the results without affecting accuracy significantly. However, neural networks have proved to be inadequate in the case of poor data availability. Research show that the human brain relies on dense connections between information nodes and a nonlinear structure to process information (Haykin, 1999). In this sense, Parry, Cao and Song (2011) define neural network as "models attempt to replicate these characteristics trough mathematical formals that link input and output variables".

Recently, Parry et al. (2011) and Chu and Cao (2011) used new methods such as probabilistic neural networks (an algorithm for forecasting new product adoption) and dynamic cubic neural network (an iterative modification mechanism for activation function and cubic architecture). Results show that these new techniques have better forecasting performance than traditional ones.

\section{Discussion and future thought-provoking lines of research}

Forecasting, especially new product forecasting, is a combination of art and science. New product development can generate competitive advantages in firms (Thomas, 1993), but poor planning leads to lengthy processes with a high risk of failure. Nowadays companies are motivated to launch new products which attract new customers and so expand their market share. In order to decrease uncertainty and risk, many companies make a huge effort to forecast accuracy using different techniques. The strengths and weaknesses of each technique are reflected in Table 2 . It is concluded that the improvement of new product forecasting can increase company competitive advantage.

According to Lawrence et al. (2006), judgment is currently recognized as an indispensable component of forecasting. In the last years, many aspects of judgmental methods have improved, especially accuracy. Feedback and expert aid facilitate the forecaster's learning process, and decomposition methods make the forecasting task easier, resulting in higher accuracy. Recent research has also found that adjustments can improve the accuracy of statistical forecasts under the right conditions. In this sense, we agree that judgmental methods will play an important role in new product forecasting, especially their combination with statistical or other methods. However, many questions remain to be answered, for example how forecasters acquire, create and apply information and knowledge to forecasting. Another line of study to pursue is the development and improvement of methods for supporting judgmental forecasters (such as new technologies or dialectical inquiry). Future 
research can also look at ways of expert selection to reduce biases associated with expert opinions.

\begin{tabular}{|c|c|c|}
\hline $\begin{array}{l}\text { TYPE OF MODELS } \\
\text { (Main objective) }\end{array}$ & STRENGTHS & WEAKNESSES \\
\hline $\begin{array}{l}\text { Judgmental } \\
\text { (Turn experience, } \\
\text { judgment and } \\
\text { intuition into a } \\
\text { formal forecast) }\end{array}$ & $\begin{array}{l}\text { Important role of management in } \\
\text { effective implementation of forecasting } \\
\text { techniques. Crucial role of knowledge of } \\
\text { context of the time series to accuracy. } \\
\text { (Webby \& O'Connor, 1996) } \\
\text { Most important method of practical sales } \\
\text { forecasting (Webby \& O'Connor, 1996) } \\
\text { Important role in macro-economic } \\
\text { forecasting (e.g. Lawrence et al., 2006) } \\
\text { Improved accuracy (Armstrong, 1983) }\end{array}$ & $\begin{array}{l}\text { Lack of reliability } \\
\text { (Makridakis \& Wheelwright, 1998) } \\
\text { Lack of external point of view } \\
\text { (Kahn, 2006) }\end{array}$ \\
\hline $\begin{array}{l}\text { Consumer/market } \\
\text { research } \\
\text { (Collect and } \\
\text { analyse } \\
\text { customer/market } \\
\text { data to make } \\
\text { forecasts) }\end{array}$ & $\begin{array}{l}\text { Consideration of the new product } \\
\text { development process (concept testing, } \\
\text { pre-test market, test market, pre-test } \\
\text { and test awareness and early sales } \\
\text { models) } \\
\text { Ease of use and real applicability in } \\
\text { companies }\end{array}$ & $\begin{array}{l}\text { Poor corporate experience of } \\
\text { forecasting software } \\
\text { High price and acting as a "black- } \\
\text { box" in companies } \\
\text { Lack of a well-tested scientific } \\
\text { basis (Schocker \& Hall, 1986) } \\
\text { Difficult applicability to "new-to- } \\
\text { the-world" products }\end{array}$ \\
\hline $\begin{array}{l}\text { Cause-effect/Time } \\
\text { Series/Explanatory } \\
\text { models } \\
\text { (Analyse sales data } \\
\text { to detect historical } \\
\text { sales patterns) }\end{array}$ & $\begin{array}{l}\text { Improved accuracy } \\
\text { Correct implementation in many types of } \\
\text { goods (e.g. consumer durables and } \\
\text { telecommunications) (Meade and Islam, } \\
2006)\end{array}$ & $\begin{array}{l}\text { Non consideration of competitive } \\
\text { reaction and economic conditions } \\
\text { Risky and misleading forecasting } \\
\text { (Parker, 1994) }\end{array}$ \\
\hline $\begin{array}{c}\text { Artificial } \\
\text { Intelligence } \\
\text { (Propose advanced } \\
\text { statistical } \\
\text { computer-based } \\
\text { models) } \\
\end{array}$ & High accuracy & $\begin{array}{l}\text { No real applicability } \\
\text { Difficulty of use for management }\end{array}$ \\
\hline
\end{tabular}

Table 2. Strengths and weaknesses of models

Many companies use decision-support systems to succeed in the market. According to Schocker and Hall (1986), products that proceed to test market should have an $80 \%$ chance of success in the market. Despite their costs, these forecasting models have become the most used models because they reduce risk. Nevertheless, many doubts exist about their applicability and usefulness. For example, many commercial forecasting software applications do not consider the variety of products and companies. More research on extending the models 
to other situations and countries would be very useful.

With regard to diffusion models, three main lines of future research are proposed:

- more rigorous and systematic assessment of models and tools,

- improvement of the validity of diffusion parameters and their factors. It is important to refine pricing and other marketing strategies, and incorporate them into forecasting. Issues like cannibalisation (the process by which a new product gains sales by diverting them from an existing product), competitor reaction patterns and supercession are also worth considering, and,

- forecasting in other geographic diffusion areas. The launch of new products and services across several countries is very common nowadays. The simultaneous forecasting of future sales poses an interesting challenge.

Finally, previous research, such as Clemen (1989) and Ozer (1999), stated that, when combined, some different and independent forecast models will average out the forecast errors. Hence, it is recommended to use more than one method in combination throughout the product development process to develop forecasts. This said, future research can compare the different models and outline specific conditions that make one preferable over another. Moreover, mechanisms for combining and updating data across time periods can be devised.

The relevance of continuing research on new product forecasting is highlighted in our article. Thus, several new, thought-provoking future lines of research are outlined. Advances would improve the performance of new products in the market and help managers make decisions and sustain competitive advantages in this challenging world.

\section{Acknowledgments}

The research presented in this paper has been supported by the Spanish Ministry of Economy and Competitivity (project DPI2010-15614). The authors are grateful to the anonymous referees who provided helpful comments on this paper. 


\section{References}

ADYAA, M.; ARMSTRONG, J.; COLLOPY, F.; KENNEDY, M. (2000). An application of rule-based forecasting to a situation lacking domain knowledge. International Journal of Forecasting, 16: 477-484. http://dx.doi.org/10.1016/S0169-2070(00)00074-1

ARMSTRONG, J.S. (1983). Relative accuracy of judgmental and extrapolative methods in forecasting annual earning. Journal of Forecasting, 2: 437-447. http://dx.doi.org/10.1002/for.3980020411

ASSMUS, G. (1984). New Product Forecasting. Journal of Forecasting, 3: 121-138. http://dx.doi.org/10.1002/for.3980030202

BASS, F.M.; TRICHY, V.K.; DIPAK, C. (1994). Why the Bass model fits without decision variables. Marketing Science, 13(3): 203. http://dx.doi.org/10.1287/mksc.13.3.203

CHING-CHIN, C.; IEONG KA IENG, A.; LING-LING, W.; LING-CHIEH, K. (2010). Designing a decision support system for new product sales forecasting. Expert Systems with applications, 37(2): 1654-1665. http://dx.doi.org/10.1016/j.eswa.2009.06.087

CHU, BS.; CAO, D-B. (2011). Dynamic Cubic Neural Network Demand Momentum for New Product Sales Forecasting. An International Interdisciplinary Journal, 14(4): 1171-1182.

CLEMEN, R.T. (1989). Combining forecasts: a review and annotated bibliography. International Journal of Forecasting, 5(4): 559-583. http://dx.doi.org/10.1016/0169-2070(89)90012-5

FADER, P.S.; HARDIE, B.G. (2001). Forecasting trial sales of new consumer packaged goods. In J.S. Armstrong (Eds.), Principles of forecasting. A handbook for researchers and practitioners (Chapter 18). Springer. http://dx.doi.org/10.1007/978-0-306-47630-3_28

FADER, P.S.; HARDIE, B.G. (2005). The value of simple models in new product forecasting and customer-base analysis. Applied Stochastic models in business and industry, 21(4): 461-473. http://dx.doi.org/10.1002/asmb.592

GARDNER, E. (2005). Exponential smoothing: the state of the art-Part II. International Journal of Forecasting, 22 (4): 1-28.

GARDNER, E.S. JR.; MCKENZIE, E. (1985). Forecasting trends in time series. Management Science, 31(10): 1237-1246. http://dx.doi.org/10.1287/mnsc.31.10.1237

GARTNER, W.B.; THOMAS, R.J. (1993). Factors affecting new product forecasting accuracy in new firms. Journal of product innovation management, 35-52. http://dx.doi.org/10.1016/07376782(93)90052-R 
HARDIE, B.G.; FADER, P.S.; WISNIEWSKY, M. (1998). An empirical comparison of new product trial forecasting models. Journal of Forecasting, 17: 209-229. http://dx.doi.org/10.1002/ (SICI)1099-131X(199806/07)17:3/4<209::AID-FOR694>3.0.CO;2-3

HAYKIN, S. (1999). Neural network: A comprehensive foundation. NJ, Prentice-Hall. Industrial Marketing Management, 28: 565-571.

KAHN, K.B. (2002). An exploratory Investigation of new product forecasting practices. The Journal of Product Innovation Management, 19: 133-143.http://dx.doi.org/10.1016/S07376782(01)00133-3

KAHN, K.B. (2006). New Product Forecasting: An Applied Approach Armonk. NY: M.E. Sharpe.

LAWRENCE, M.; GOODWIN, P.; O'CONNOR, M.; ÖNKAL, D. (2006). Judgmental forecasting: A review of progress over the last 25 years. International Journal of Forecasting, 22(1): 493-518. http://dx.doi.org/10.1016/j.ijforecast.2006.03.007

LILIEN, G.L.; RANGASWAMY, A.; DE BRUYN, A. (2007). Marketing Engineering. Retrieved 6th de May de 2011, from Principles of Marketing Engineering Technical Notes, available online at: http://www.mktgeng.com/intro_principlestechnicalnotes.cfm

LINSTONE, H.A.; TUROFF, M. (1975). Introduction. In H.A. Linstone \& M. Turoff (Eds.). The Delphi method: Techniques and applications. MA: Addison-Wesley Publishing Company.

LYNN, G.S.; SCHNAARS, S.P.; SKOV, R.B. (1999). A Survey of New Product Forecasting Practices in Industrial High Technology and Low Technology Businesses - Traditional versus Multiattribute Approaches. Industrial Marketing Management, 28(6): 565-571. http://dx.doi.org/10.1016/S0019-8501(98)00027-3

M4-Competition (2010). Available online at: http://m4competition.com/ (Last access date: May 31st, 2011).

MAHAJAN, V. (1990). New product models: Practice, shortcomings and desired improvements. Journal of Product Innovation Management, 9: 128-139. http://dx.doi.org/10.1016/07376782(92)90004-V

MAHAJAN, V.; WIND, Y. (1988). New product forecasting models. Directions for research and implementation. International Journal of Forecasting, 4: 341-358. http://dx.doi.org/10.1016/0169-2070(88)90102-1

MAHAJAN, V.; MULLER, E.; BASS, FM. (1990). New product diffusion models in marketing. A review, and direction for research. Journal of Marketing, 54(1): 1-26. http://dx.doi.org/10.2307/1252170

MAKRIDAKIS, S.; WHEELWRIGHT, S.C. (1998). Métodos de pronósticos. Limusa: Noriega editores. Management Science, 31: 1237-1246. 
MEADE, N.; ISLAM, T. (2006). Modelling and forecasting the diffusion of innovation -A 25-year review-. International Journal of Forecasting, 22: 519-545. http://dx.doi.org/10.1016/j.ijforecast.2006.01.005

MENTZER, T.; MOON, M. (2005). Sales forecasting management: A demand management approach. Sage Publications, Inc.

MICHELFELDER, R.A.; MORRIN, M. (2006). Intellectual Property Management Institute., from Overview of New Product Diffusion Sales Forecasting Models, available online at: http://www.ipinstitute.com/onpdsfm.htm. (Last access date: 26th April, 2011).

OZER, M. (1999). A survey of New Product Evaluation Models. Journal Product Innovation Management, 16: 77-94. http://dx.doi.org/10.1016/S0737-6782(98)00037-X

PARKER, P.M. (1994). Aggregate diffusion forecasting models in marketing: A critical review. International Journal of Forecasting, 10: 353-380. http://dx.doi.org/10.1016/0169-2070(94)900132

PARRY, M.E.; CAO, Q.; SONG, M. (2011). Forecasting New Product Adoption with Probabilistic Neural Networks. Journal Product Innovation Management, 28(1): 78-88. http://dx.doi.org/10.1111/j.1540-5885.2011.00862.x

PRINGLE，L.G.; WILSON, R.; BRODY, E.D. (1982). NEWS: A decision-oriented model for new product analysis. Marketing science, 1: 1-29. http://dx.doi.org/10.1287/mksc.1.1.1

SANDERS, N.R.; MANRODT, K.B. (2003). The efficacy of using judgmental versus quantitative forecasting methods in practice. The International Journal of Management Science, 31: 511-522.

SCHOCKER, A.D.; HALL, W.G. (1986). Pretest market models: A critical evaluation. Journal of Product Innovation Management, 3: 86-107. http://dx.doi.org/10.1016/0737-6782(86)90031-7

SOOD, A.; JAMES, G.M.; TELLIS, G.J. (2009). Functional regression: a new model for predicting market penetration of new products. Marketing Science, 28(1): 36-51. http://dx.doi.org/10.1287/mksc.1080.0382

THOMAS, R.J. (1993). New product development: Managing and forecasting for strategic success. NY: Wiley.

URBAN, G.L.; HAUSER, J.R. (1993). Pretest market forecasting. In Design and marketing of new products (chapter 16).Prentice-Hall Inc.

URBAN, G.L.; KATZ, G.M. (1983). Pre-test market models: validation and managerial implications. Journal of Marketing Research, 20(3): 221-234. http://dx.doi.org/10.2307/3151826 
WEBBY, R.; O'CONNOR, M. (1996). Judgmental and statistical time series forecasting: a review of literature. International Journal of Forecasting, 12: 91-118. http://dx.doi.org/10.1016/01692070(95)00644-3

WHERRY, J.S. (2006). Simulated test-marketing: its evolution and current state in the industry. MIT Sloan School of Management, 1-12. Available online at: http://dspace.mit.edu/bitstream/handle/1721.1/37225/85813336.pdf (Last access date: $24^{\text {th }}$ January, 2014).

WIND, J.; MAHAJAN, V. (1997). Issues and opportunities in new product development: An introduction to the special issue. Journal of Marketing Research, 34: 1-12. http://dx.doi.org/10.2307/3152060

WIND, Y. (1974). A Note on the Classification and Evaluation of New Product Forecasting Models. Paper presented at the American Marketing Association Conference. 